\title{
Une cohorte perdue
}

Les opinions exprimées dans cet éditorial sont celles de l'auteur et ne représentent pas nécessairement celles de l'Association médicale canadienne ou ses filiales.

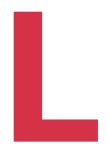

a maladie à coronavirus 2019 (COVID-19) s'impose de manière encombrante dans de nombreux milieux. Les répercussions dans le milieu médical et social engendrées par le manque de préparation contre une telle maladie a asséné un coup brutal à la population. La situation a modifié nos manières d'interagir et de socialiser, et même le fonctionnement de nos familles. La réalité, c'est que la pandémie n'est pas terminée, loin de là, et ce, même si un vaccin est approuvé; l'avenir nous réserve beaucoup plus d'incertitude que ce que nous sommes prêts à accepter. La pandémie a pris par surprise les plus éminents experts l'Organisation mondiale de la Santé, les Centers for Disease Control and Prevention, Santé Canada, les ministères de la Santé provinciaux ainsi que d'autres organisations. Malheureusement, la prochaine génération de médecins a été durement touchée par cette maladie et les processus en place (ou manquants) pour l'affronter.

La prochaine génération de médecins devra être prête à affronter les pandémies à venir. Nos successeurs vivront dans un monde d'équipements de protection individuelle (EPI) et de dangers liés aux gouttelettes et aux aérosols bien plus que nous. La COVID-19 est une pandémie meurtrière, mais elle peut être contrôlée par l'utilisation d'EPI et l'adoption de mesures sanitaires de base permettant de réduire la transmission du virus. On ne parle pas de l'Ebola - même si cette prochaine génération pourrait avoir à affronter une telle maladie.

Les études de médecine doivent préparer les étudiants et les résidents à pratiquer dans des conditions pandémiques, et ces enseignements ne doivent jamais être interrompus, pandémie ou pas. La plupart des établissements ont pris la voie contraire pendant la COVID-19. La réaction à la pandémie a été de renvoyer les étudiants chez eux. Certes, le but était de les protéger, et la pénurie d'EPI a contribué à cette décision. N'en demeure pas moins que les étudiants ont pris du retard. Les stages électifs ont été écourtés — et pas seulement les stages à l'étranger! Les spécialités médicales dont l'admission est très contingentée exigent que les candidats aient réalisé plusieurs stages électifs dans plusieurs établissements pour maximiser le succès du jumelage. Et, ça, c'est seulement pour les étudiants qui ont la chance de déjà savoir dans quelle spécialité ils veulent se diriger. Qu'en est-il de ceux qui n'ont toujours pas fait un choix et qui doivent être exposés aux différentes spécialités pour prendre cette décision si cruciale dans leur vie?

Les étudiants doivent composer avec cette situation dans un contexte d'hypocrisie de la part des administrations uni- versitaires. Le gouvernement du Québec, par exemple, a demandé aux étudiants d'apporter leur aide bénévole dans les centres de soins de longue durée au plus fort de la crise - et ils ont répondu présents. Aucune administration n'a protesté que c'était trop dangereux, malgré les mauvaises conditions de travail bien documentées et l'important taux de décès en soins de longue durée. Alors pourquoi les étudiants ne peuvent-ils pas réintégrer leur programme de formation maintenant que les milieux de travail et d'enseignement sont beaucoup mieux outillés?

Pour les étudiants de deuxième année, le passage déterminant à la médecine clinique a été annulé, et les étudiants ont été renvoyés chez eux pour la majorité de leur stage de 24 semaines. Définitivement, cette situation élimine le modèle d'enseignement traditionnel étudiant-mentor. Quelques occasions d'apprentissages en ligne ont bien été proposées pour contrer ces lacunes, mais ces stages demeurent une excellente occasion pour les étudiants de découvrir concrètement les soins aux patients. Les cours en ligne non validés pourraient ne pas être le meilleur moyen d'enseigner ces premiers contacts si essentiels. Ils peuvent bien sûr rendre efficacement certaines interactions avec les patients, mais certainement pas toutes les bizarreries de la vraie vie.

Ce ne sont pas seulement les premières années de formation clinique qui ont été compromises. Les étudiants de dernière année ont aussi vu leur formation écourtée sans plan de secours. Ainsi, comparativement à leurs prédécesseurs, ces étudiants obtiennent leur diplôme en ayant assumé moins de responsabilités cliniques et connu une exposition moindre à différents milieux qui pourraient guider leur choix de carrière et de pratique en médecine. C'est loin d'être idéal... Une autre cohorte d'étudiants en médecine commencera bientôt son parcours. Ces étudiants sont une ressource précieuse et représentent l'avenir de notre système de santé. Avons-nous fait des changements pour éviter de compromettre cette cohorte aussi?

\section{Edward J. Harvey, MD}

Affiliation: Corédacteur en chef, fournal canadien de chirurgie.

Intérêts concurrents : E.J. Harvey est médecin chef chez Greybox Solutions; il est cofondateur et directeur de l'innovation médicale de NXTSens Inc, cofondateur et médecin chef de MY01 Inc. et cofondateur et directeur de Strathera Inc. Il bénéficie du soutien institutionnel de J \& J, DePuy Synthes, Stryker et Zimmer, et il fait partie du conseil d'administration de l'Orthopedic Trauma Association et de l'Association canadienne d'orthopédie.

DOI: $10.1503 /$ cjs.020920 